\title{
What Good is Meaning in Life?
}

Christopher Woodard

Forthcoming in De Ethica. Please cite the published version.

Abstract: Most philosophers writing on meaning in life agree that it is a distinct kind of final value. This consensus view has two components: the 'final value claim' that meaning in life is a kind of final value, and the 'distinctness claim' that it is distinct from all other kinds of final value. This paper discusses some difficulties in vindicating both claims at once. One way to underscore the distinctness of meaning, for example, is to retain a feature of our pretheoretical concept of meaning in life, according to which the least possible quantity of meaning is meaninglessness. Unfortunately, this makes it harder to defend the claim that meaning is a kind of final value. On the other hand, revising the concept to allow for negative meaning renders meaning closer in structure to other kinds of final value, but also makes it harder to defend the distinctness claim. In light of these difficulties, the paper explores the prospects of a theory of meaning in life which departs from the consensus view by rejecting the final value claim. On such a view, the value of meaning in life is entirely instrumental.

Key words: Meaning in life; final value; instrumental value; negative meaning; meaninglessness

\section{Introduction}

Philosophers who write about meaning in life disagree about many things, but they tend to agree on this: that it is a distinct kind of final value of lives. Here 'final value' means a kind of value that something could have independently of its causal consequences. Final value is a kind of value that something has for its own sake - to be contrasted with instrumental value, which is value in virtue of causing something with final value. One component of the shared assumption, then, is the claim that a life's having meaning, or an activity's having meaning, endows it with value independently of what the life or activity causes. I will call this 'the final value claim' about meaning in life.

The shared assumption has a second component. According to what I will call 'the distinctness claim', meaning in life is distinct from all other kinds of final value. We are used to the idea that lives may have different kinds of final value: for example, they may be rich in well-being (good for the persons whose lives they are), or they may be morally good (good in respect of whatever matters morally), or they may perhaps have aesthetic or epistemic value (they may be beautiful or instructive). These different kinds of value, if all are genuine, may 
interact in interesting ways. They may sometimes conflict with each other, as when we think that someone lived a life that was good for her but bad for others; or we think that someone's life was instructive even though, or perhaps because, it contained significant suffering. According to the distinctness claim about meaning in life, meaning is distinct in the sense that it is not reducible to any other kind of value, or any combination of other kinds of value. To account for all of the value that lives can have, we have to add meaning to the balance sheet. As with the other values we just considered, the distinctness claim is compatible with believing that meaning in life is interestingly related to other kinds of final value. It could be, for example, that meaning in life contributes to well-being. ${ }^{1}$ The distinctness claim denies that meaning is reducible to other values, but not that it is related to other values.

The shared assumption, then, has two components: the final value claim, and the distinctness claim. For ease of reference, I shall refer to this combination of claims as 'the consensus view'. It is a kind of consensus, among those who theorise about meaning in life. ${ }^{2}$ On the other hand, this is only a local consensus, and 'the consensus view' is not quite universal even among this group. Among many philosophers who do not theorise about meaning in life, the consensus appears to be some form of scepticism about the phenomenon. It is common to hear the view expressed, for example, that lives are not the sort of thing that can have meaning. Moreover, even among those who do theorise about meaning in life, some demur from the consensus. For example, Robert Nozick distinguishes between meaning on one hand and value on the other, treating them as distinct kinds of 'worth' ${ }^{3}$ Recently, Tatjana Višak has argued that the concept of meaning in life is best understood as providing an alternative way to refer to normative reasons for action. Since the relationship between

\footnotetext{
${ }^{1}$ Susan Wolf and Thaddeus Metz claim that it does. This is compatible with what I am calling the consensus view. See Susan Wolf, 'Happiness and Meaning: Two Aspects of the Good Life', Social Philosophy and Policy 14 (1997), pp. 207-25 and Thaddeus Metz, Meaning in Life (Oxford: Oxford University Press, 2013), p. 74 n. 11.

${ }^{2}$ Examples of the consensus view include Berit Brogaard and Barry Smith, 'On Luck, Responsibility and the Meaning of Life', Philosophical Papers 34: 3 (2005), pp. 443-458; David Matheson, 'Creativity and Meaning in Life', Ratio online first (2016) doi:10.1111/rati.12153; Metz, Meaning in Life, Ch. 4; Aaron Smuts, 'The Good Cause Account of the Meaning of Life', The Southern Journal of Philosophy 51: 4 (2013), pp. 536-562; Frans Svensson, 'Why Subjectivism About Meaning In Life Might Not Be So Bad After All', unpublished MS; Wolf, 'Happiness and Meaning'; Susan Wolf, Meaning in Life and Why it Matters (Princeton: Princeton University Press, 2010).

${ }^{3}$ According to Nozick, value is a kind of worth that involves order within limits, while meaning is a kind of worth that involves transcending limits. See Robert Nozick, Philosophical Explanations (Cambridge, MA: Belknap Press, 1981), pp. 610-19.
} 
reasons and value is a further question, her view is committed neither to the final value claim nor to the distinctness claim. ${ }^{4}$

We should not accept scepticism about meaning in life just because lives do not have syntactic structure, or do not in other ways resemble other things that we take to have meaning. That is a flat-footed and ultimately unconvincing way of thinking about the issues. Even if philosophers often take this sort of scepticism as a default view, many nonphilosophers do not. Many people evidently judge that some lives or activities are more or less meaningful than others. Scepticism about the putative object of these judgements is thus highly revisionary of common sense. For that reason, we should treat it as possibly correct but in need of significant theoretical motivation. Mere lack of resemblance between lives and other entities we take to be meaningful is not, I take it, sufficient motivation. That narrow ground for scepticism simply betrays uncharitable literal-mindedness on the part of the sceptic. ${ }^{5}$

In this paper I will assume that meaning in life is a real phenomenon, without either arguing for that assumption or endorsing any particular theory of the nature of meaning in life. My focus instead will be on the value of meaning in life. I will argue that the consensus view faces a serious challenge, which consists in defending both the final value claim and the distinctness claim at once. The first half of the paper (sections 2-4) explains this challenge, concluding that it is at least not obvious how the consensus view can meet it. This conclusion motivates discussion in the second half of the paper (sections 5-6) of one way of departing from the consensus view, which consists in dropping the final value claim. Meaning in life may be valuable without itself being a kind of final value. Its value may be purely instrumental, though none the less real for all that. ${ }^{6}$

\footnotetext{
${ }^{4}$ See Tatjana Višak, 'Understanding Meaning of Life in Terms of Reasons for Action', Journal of Value Inquiry 51: 3 (2017), pp. 507-30. Her discussion is addressed to the conceptual question of how to articulate the concept of meaning in life, rather than the substantive question of what meaning in life consists in. Nevertheless, Višak's answer to the conceptual question suggests a way of conceiving meaning in life that rejects what I have called the consensus view.

${ }^{5}$ This is especially so in light of the fact that a significant body of recent philosophical writing on meaning in life has shown many promising ways in which we can try to make sense of common judgements about it. For useful surveys, see Thaddeus Metz 'Recent Work on the Meaning of Life', Ethics 112 (2002), pp. 781-814; Thaddeus Metz, 'New Developments in the Meaning of Life', Philosophy Compass 2 (2007), pp. 196-217.

${ }^{6}$ How is it possible to reach any conclusion about the value of $\mathrm{X}$ without first knowing the nature of $\mathrm{X}$ ? I am assuming that meaning in life is a real phenomenon, and that it is the object of ordinary judgements about which lives and activities are meaningful. My claims about value are ultimately claims about what we really think about the object of these judgements: I claim that the consensus
} 


\section{A challenge for the consensus view}

The challenge for the consensus view is simply to vindicate both of its constituent claims at once. That is, the challenge is to offer reasons for thinking that meaning in life is both a kind of final value and that it is distinct from other kinds of final value, such as well-being or moral value.

The challenge gains some traction initially because the leading theories of meaning portray it in a way that resembles other kinds of final value, and the leading examples used in discussion of these theories often seem interpretable in terms of other kinds of final value. For example, Thaddeus Metz has distinguished theories of meaning in life according to whether they are supernaturalist or naturalist. Within the naturalist category, the chief division is between subjective and objective theories. Metz characterises the difference between these as follows:

A subjective theory maintains that what makes a life meaningful depends on the subject ... More specifically, it is the view that whether a life is meaningful essentially is a function of whether it is (or its parts are) the object of some proattitude or other. An objectivist can grant that a certain positive mental orientation helps to constitute life's meaning; subjectivism's defining point is that such a disposition is sufficient for meaning in life. ${ }^{7}$

It is then possible to distinguish different kinds of subjectivism, according to which proattitude is said to be crucial for meaning, and to distinguish different kinds of objectivism, according to whether a pro-attitude is necessary, and according to which other conditions are said to be necessary for meaning to obtain. ${ }^{8}$

These different kinds of theory of meaning in life certainly resemble familiar kinds of theory of well-being. It is common to distinguish subjective and objective theories of well-

view wrongly interprets common belief about meaning in life when it treats it as committed to the idea that meaning is a distinct kind of final value of lives. So we should not build that assumption into our theorising about meaning in life. On the other hand, common belief about meaning in life may turn out to be wrong: if we discover the nature of meaning in life, we may have to revise our views, and acknowledge that it has final value after all. My conclusion in this paper is thus about what we now have reason to believe about meaning in life.

${ }^{7}$ Metz, 'Recent Work', pp. 792-3.

${ }^{8}$ See Metz, 'Recent Work', pp. 792-801. 
being, for example, and to make further distinctions within those categories along the same sorts of lines as those just mentioned in the case of theories of meaning. ${ }^{9}$ Moreover, the examples given of lives that are rich in meaning also appear to be lives that are valuable in other ways. For example, Susan Wolf cites Gandhi, Mother Teresa, and Einstein as 'unquestionably meaningful lives (if any are) ${ }^{10}$ Presumably, if we are disposed to judge these lives as meaningful we will also be disposed to judge them as good in terms of one or more other kinds of final value, such as well-being, moral value, or epistemic value.

Thus there is resemblance both between the leading theories of meaning in life and the leading theories of other kinds of value of lives, and between the alleged paradigm cases of meaning and the alleged paradigm cases of other kinds of value. This naturally prompts the question of whether meaning is both a kind of final value and genuinely distinct from other kinds of it. ${ }^{11}$

We should not misunderstand the nature of this challenge. First, it should not be taken to apply uniquely to meaning in life, on the grounds that meaning in life is (as it were) a late candidate to enter the roster of final values recognised in ethical theories. There is no queue to enter the pantheon. Ultimately the question is simply which kinds of final value there are, and it could be that late entrants do a better job of picking those out than is done by more familiar concepts. We should not prioritise more established candidates just because they are more familiar. All candidate final values face the same challenge, then, though some might find it easier to meet than others.

Second, I should emphasise that I am describing a challenge for the consensus view, not seeking to demonstrate that it cannot possibly meet this challenge. I take the resemblances we have just noted to suggest that this is a genuine challenge, but I do not take them to show that, all things considered, meaning is not a distinct final value. They raise the salience of that question without answering it.

\footnotetext{
${ }^{9}$ For example, see Dale Dorsey, 'Subjectivism without Desire', Philosophical Review 121 (2012), pp. 407-42 at p. 407. For a different way to distinguish subjective and objective theories of wellbeing, see L. Wayne Sumner, Welfare, Happiness, and Ethics (Oxford: Clarendon Press, 1996), Ch. 2 .

${ }^{10}$ Wolf, 'Happiness and Meaning', p. 209.

${ }^{11}$ Stephen Kershnar raises an objection of this sort against Metz's views in his paper, 'Thad Metz's Fundamentality Theory of Meaning in Life: A Critical Review', Science, Religion and Culture 1 (2014), pp. 97-100. Thaddeus Metz responds in his paper, 'Meaning as a Distinct and Fundamental Value: Reply to Kershnar', Science, Religion and Culture 1 (2014), pp. 101-106.
} 
Finally, it is important to note that it would not suffice, as a response to the challenge of showing that meaning is both a kind of final value and distinct from others, that there is no other single kind of final value that plausibly explains our judgements about meaning in life. ${ }^{12}$ Those judgements might be explicable in terms of a number of other kinds of final value. One way that meaning could fail to be distinct is for our judgements employing the concept of meaning in life to be sometimes about well-being and sometimes about moral value, for example.

\section{Meaninglessness}

What is the least quantity of meaning that a life or activity may have? According to common sense, it is nil. An important structural feature of our pre-theoretical concept of meaning is that it allows no negative meaning. There is nothing less meaningful than meaninglessness. Sisyphus's meaningless activity has as little meaning as it is possible for any activity to have.

One strategy in response to the challenge to demonstrate the distinctness of meaning would be to emphasise this feature of our pre-theoretical concept of meaning in life. This would serve to distinguish it decisively from well-being, moral value, and all of the other plausible candidates for kinds of final value of lives. Our concepts of these other candidates all allow for negative values: a life of unremitting suffering has negative well-being, for example, and a wicked life is not merely one that lacks moral value, but one that has moral disvalue. Not only that, but these negative values can increase without any apparent limit. ${ }^{13}$ We can just keep piling more suffering or wickedness into them. If one kind of value has an absolute minimum, while another can keep getting worse without apparent limit, there is reason to think that they are not the same kind of value. So if meaning in life is whatever answers to our pre-theoretical concept, it cannot be the same thing as well-being, moral value, or any of the other plausible candidates for kinds of final value of lives.

\footnotetext{
${ }^{12}$ Metz's reply to Kershnar appears to take this form. He argues, first, that meaning in life is not reducible to the intrinsic value of a life (understood as the value a life has in virtue of its intrinsic properties) and then, second, that it is not reducible to well-being. See Metz, 'Meaning as a Distinct and Fundamental Value', pp. 101-3.

${ }^{13}$ The idea of meaninglessness, as it is usually understood, combines two features. It is (a) the least possible quantity of meaning, and (b) zero meaning. The feature that I take to be relevant for present purposes is (a). But for simplicity I will refer to it by saying that our pre-theoretical concept of meaning in life allows 'no negative meaning'.
} 
We might wonder whether this feature could make any sense, and so whether retaining it is a genuine option for theories of meaning. What could explain the apparent bottoming-out of meaning in meaninglessness? One obvious way to make sense of it is to assimilate it to mattering, as that is usually understood. To matter in this sense is to have practical significance of either positive or negative valence. Bad things matter, just as good things do. But some things do not matter at all, and that is the least possible quantity of mattering. Perhaps meaning is like that.

If we adopt a theory of meaning in life with this feature, we can distinguish it from well-being, moral value, and other candidate final values. But we would not thereby escape the challenge to the consensus view. Understood in this way, meaning would not only appear to be distinct from these specific other final values, but from all other candidate final values. In general, for any kind of final value, we tend to think that things can keep getting worse in that respect. Things can get more and more unjust or unequal; they can get more and more ugly; there is no maximum quantity of suffering. Other final values do not appear to bottomout. Mattering, indeed, is not a kind of final value-but instead a function of other values (or other considerations). Something matters to the extent that it has any kind of value or disvalue.

So, retaining this feature supports the distinctness claim but threatens to undermine the final value claim. Again, this is hardly conclusive. Perhaps the appearance that other kinds of final value do not bottom-out is deceptive..$^{14}$ Or perhaps meaning is unique amongst final values in bottoming-out. However, we can at least say that it is not obvious how this way of defending the distinctness claim can be combined with a defence of the final value claim.

\section{Negative meaning?}

Perhaps for this reason, some theorists of meaning propose that there is, contrary to common assumption, negative meaning. Thaddeus Metz argues that just as some actions improve one's standing with respect to meaning in life, and others are neutral, a third category of actions worsens one's standing with respect to meaning in life. For example, oversleeping is neutral

\footnotetext{
${ }^{14}$ Some candidate final values may have the appearance of bottoming-out, but on reflection do not do so. For example, we might at first think that there is a least possible amount of autonomy. But this does not seem true on further reflection: we can always imagine making things worse with respect to autonomy by adding more manipulation or deception to the agent's circumstances.
} 
with respect to meaning, while blowing up the Sphinx for fun worsens one's situation. Interestingly, Metz expresses this idea by saying that this action 'anti-matters', or has negative meaning. Moreover, a life full of actions like this would be one of negative meaning in life, which is to say that it would be worse, with respect to meaning, than a meaningless life. ${ }^{15}$ Stephen Campbell and Sven Nyholm have recently made a very similar argument. ${ }^{16}$

Whatever the other merits or demerits of this suggestion, it is self-consciously revisionary. Metz and Campbell and Nyholm realise that our ordinary concepts of meaning in life (or of mattering) do not allow negative meaning (or anti-mattering). Of course, the fact that it is revisionary does not imply that it is unjustified. But it does have some implications for our reasons to accept these theories. Many ethicists accept a methodology according to which one desideratum is to make as much sense as possible of ordinary ethical judgements. Insofar as the idea of negative meaning is out of step with those judgements, it seems to do badly with respect to that desideratum, and so must be justified, if at all, by compensating theoretical advantages. But if we examine the cases that are presented as exemplifying negative meaning, it is not obvious what the theoretical advantages of accepting negative meaning are supposed to be. For example, in addition to blowing up the Sphinx for fun, Metz gives as examples of actions with negative meaning burning science books, and 'killing innocents and using their blood in one's paintings to make a statement about the value of human life'. ${ }^{17}$ In all of these examples the action is undoubtedly bad, but in none of them is it clear that we have to go beyond moral value, epistemic value, or aesthetic value to explain why it is bad.

More generally, accepting negative meaning makes the concept of meaning in life resemble other candidate final values more closely. That is good news if we wish to claim that it is a kind of final value, but it also seems to make it harder to vindicate the claim of distinctness.

\footnotetext{
${ }^{15}$ See Metz, Meaning in Life, pp. 63-4, 233-36.

${ }^{16}$ Campbell and Nyholm give essentially the same argument as Metz for belief in negative meaning, which they call 'anti-meaning': 'To be meaningful, it is not enough that a life is "full of meaning." It must also be the case that it is not full of anti-meaning. Thus, it appears to be impossible to assess the overall meaningfulness of lives without taking anti-meaning into account'. Stephen Campbell and Sven Nyholm, 'Anti-Meaning and Why It Matters', Journal of the American Philosophical Association 1 (2015), pp. 694-711, at pp. 704-5. According to this argument, we need to accept the existence of negative meaning in order to account properly for the meaningfulness of whole lives.

${ }^{17}$ Metz, Meaning in Life, pp. 64, 234.
} 


\section{The instrumental value of meaning in life}

So far I have described a challenge to the consensus view, and considered two possible responses to that challenge. One response was to try to vindicate the distinctness claim by emphasising that our pre-theoretical concept does not allow negative meaning. The downside of that response is that it seems to make it harder to vindicate the final value claim. The second response was to try to vindicate the final value claim by revising our pre-theoretical concept to allow for negative meaning. The downside of that response is that it seems to make it harder to vindicate the distinctness claim.

We have here the appearance of a dilemma for the consensus view. Since we have considered only two broad kinds of response to the original challenge, we should not peremptorily conclude that this is a genuine and inescapable dilemma. But we can say, more tentatively, that it is not yet obvious how the original challenge to the consensus view can be met.

With that in mind, we might consider various ways of departing from the consensus view. One way would be to give up on the distinctness claim, and assimilate meaning in life to some other value or values. To do that would involve recognising negative meaning, however, and so would share in the revisionism that idea involves. It would also make the concept of meaning in life in principle dispensable to ethics.

In the remainder I will argue that we should consider giving up the final value claim. Of course, this would not entail denying that meaning in life has value; instead, it would be to think of its value as purely instrumental. As I shall try to emphasise, something is not less valuable - nor its value less real-just because its value is purely instrumental. Aversion to the merely instrumental is a potentially distorting influence in ethics. Moreover, an advantage of giving up the final value claim is that it may enable us to vindicate the distinctness of meaning in life and its indispensability as a concept.

Recall that we earlier assumed that meaning in life is a real phenomenon, in the sense that some lives or activities are more meaningful than others. If we make that assumption, how might we expect meaning in life to have instrumental value? It must be through some causal chain, from whichever properties realise meaning in life to something that has final value.

One way in which this causal chain could go is via a sense of meaningfulness. That is, it could be that meaning in life causes good things in part by causing a sense of meaningfulness, which is either a final good itself or is a cause of some other final good, or both. A 'sense of meaningfulness' is that psychological state in which one's activities or life 
seem meaningful to one. I will not try to characterise this psychological state fully, but I will assume that it has cognitive, conative, and affective components. It involves being disposed to believe that what one is doing is meaningful to some degree, to be motivated to do it for that reason, and associated moods and emotional states. ${ }^{18}$

Finding one's life and activities to be meaningful certainly seems to be valuable for many people in many circumstances. It can help to generate and sustain motivation, for example..$^{19}$ It can make difficult or challenging activity pleasant or satisfying.$^{20}$ It can also help to bring narrative unity to a life or a period of one's life, as when someone says 'during my thirties I was establishing my career' or 'being a parent took up all of my time then'. The sense of narrative unity - which is lacking in a purely episodic life-seems to be important for many people. ${ }^{21}$

These benefits of the sense of meaning confer instrumental value on meaning itself insofar as meaning causes the sense of meaning. It may be helpful to draw an analogy here with something's being funny. Whatever the proper philosophical account of what it takes for something to be funny, it is possible for any individual to be wrong about which things are funny, since anyone can have a sense of humour failure. Similarly, it seems safe to assume that anyone can have a sense of meaning failure. But we may speculate that anyone would be

\footnotetext{
${ }^{18}$ Antti Kauppinen, 'Meaning and the Good Life', online at https://www.academia.edu/28978139/Meaning_and_the_Good_Life accessed 2017.03.13,pp. 4-7 offers a good characterisation of the sense of meaningfulness. On the relationship between emotions and the sense of meaningfulness, see David Tang, Nicholas J. Kelley, Joshua A. Hicks, and Eddie Harmon-Jones, 'Emotions and Meaning in Life: A Motivational Perspective', in The Experience of Meaning in Life: Classical Perspectives, Emerging Themes, and Controversies, edited by Joshua A. Hicks and Clay Routledge (Dordrecht: Springer, 2013), pp. 117-128.

${ }^{19}$ A. Will Crescioni and Roy F. Baumeister, 'The Four Needs for Meaning, the Value Gap, and How (and Whether) Society Can Fill the Void', in The Experience of Meaning in Life: Classical Perspectives, Emerging Themes, and Controversies, edited by Joshua A. Hicks and Clay Routledge (Dordrecht: Springer, 2013) pp. 3-15, at p. 3 report empirical research on the beneficial effects of a sense of meaningfulness. Kauppinen, 'Meaning and the Good Life' emphasises its motivational importance.

${ }^{20}$ Compare Rawls on what he calls the Aristotelian Principle: 'other things equal, human beings enjoy the exercise of their realized capacities (their innate or trained abilities), and this enjoyment increases the more the capacity is realized, or the greater its complexity'. John Rawls, A Theory of Justice, revised edition (Cambridge, MA: Belknap Press, 1999), p. 374. If more challenging activities tend to be more meaningful, the instrumental value of meaning may help to explain the Aristotelian Principle.

${ }^{21}$ Not all: see Galen Strawson, 'Against Narrativity', Ratio XVII (2004), pp. 428-52. I am grateful to Frans Svensson for bringing this paper to my attention.
} 
more likely to find something funny if it is indeed funny, and that anyone would be more likely to find something meaningful if it is indeed meaningful. These causal hypotheses, if true, would enable us to explain the value of something's being funny or meaningful in terms of the value of someone's finding it funny or meaningful.

We should not overstate the instrumental value of meaning in life. It seems possible, and even common, for people to be highly motivated by things that are not, we believe, genuinely meaningful. This could be because the person wrongly finds them to be meaningful. This is a tempting, though perhaps false, interpretation of many cases in which someone develops a strong interest in collecting something, such as stamps or restaurant menus. ${ }^{22}$ Alternatively, it could be because the person is motivated independently of having a sense of meaningfulness. Not everyone has the acute sensitivity to the sense of meaningfulness displayed by characters in nineteenth century Russian novels. ${ }^{23}$

Nevertheless, it is plausible both that meaningfulness tends to cause and sustain the sense of meaningfulness, and that the sense of meaningfulness is valuable (either instrumentally, or instrumentally and finally). Thus it is plausible that meaning in life has some instrumental value.

\section{Bad meaning}

We are exploring the prospects of a theory of meaning in life that gives up the final value claim. I have just argued that it is plausible to think that meaning has instrumental value. This might encourage us to hope that all of the value of meaning in life can be explained while denying the final value claim.

Whether we can do that depends, of course, on whether meaning in life has any final value in addition to its instrumental value. One way to address this issue would be to describe a case in which a life, or part of a life, is meaningful, and yet for some reason this meaning has no causal consequences. Were we to judge that this meaning is nonetheless valuable, that would be evidence that it has final value. However, it is very difficult to describe such a case convincingly. It is hard to describe a life or any part of a life which is both meaningful and also such that the meaning it contains has no consequences.

\footnotetext{
${ }^{22}$ Collecting seems on one hand continuous with the archetypal meaningless activity of counting blades of grass, yet on the other hand continuous with the presumably meaningful activity of archiving.

${ }^{23}$ This observation is due to Kauppinen, 'Meaning and the Good Life', p. 1.
} 
A second kind of test case avoids this difficulty. We have been exploring the idea that meaning sometimes has instrumental value. Usually, things that sometimes have instrumental value can have instrumental disvalue on other occasions, because a change in circumstances changes their effects. If we could describe a case in which meaning in life is instrumentally disvaluable, we would have a different test case for the claim that meaning has final value. If meaning has final value, the meaning in this case should be a mitigating factor, to set against its instrumental disvalue. If we were to judge that there is no such mitigating factor, then we would not need to endorse the final value claim in order to explain the value that, we judge, meaning in life has.

Given our account of the instrumental value of meaning in life, we should indeed expect that it can also have instrumental disvalue. For example, it is plausible that someone could be more strongly motivated by a bad activity that is meaningful than by an otherwise similar bad activity that is meaningless. Meaning may then cause more zealous and effective pursuit of the bad activity. Alternatively, meaning may distract someone from important considerations, and a sense of meaningfulness may make someone arrogant or insensitive. ${ }^{24}$ In one or more of these ways, it seems, meaning may have instrumental disvalue.

Consider, then, two torturers. One of them, Eugene, is a docile follower of commands who simply does whatever he is told to do. The other, Frederick, is a philosophical anarchist, who will execute a command only if he has some independent motivation to do so. Eugene and Frederick are instructed to commit exactly the same acts of torture, and they do so, with exactly the same effects. But whereas Eugene does this simply because he is instructed to do it, Frederick does it only because he considers it to be part of his ongoing project of researching and practising the methods of torture used in the Spanish Inquisition. After work each night he sustains his sense of meaningfulness by reading obscure history books into the early hours. Without this sense of meaningfulness he could not bring himself to turn the screw on his victims.

Frederick's torturing activities are, I assume, more meaningful than Eugene's. That is, it is not merely that they seem to him to be meaningful, while nothing seems meaningful to Eugene. Frederick takes them to be meaningful because they are meaningful. He is engaged in a complex practical and intellectual activity that challenges his powers and requires planning and sustained effort. These features, I assume, are signs that his activities have

\footnotetext{
${ }^{24}$ This is one possible interpretation of the story of Gaugin's desertion of his family, as told by Bernard Williams in his paper 'Moral Luck', which is most easily accessible in his book Moral Luck: Philosophical Papers 1973-1980 (Cambridge: Cambridge University Press, 1981), pp. 2039.
} 
meaning. This meaning sustains his sense of meaning, and thereby causes him to commit acts of torture he would not otherwise commit.

Of course, not everyone will accept that Frederick's activities are meaningful. Moreover, it may seem extravagant to make this claim without committing to a positive theory of the nature of meaning in life. But note that we can vary the details of the case according to our theory of the nature of meaning. All that is required is that there is a way of carrying out an unambiguously bad activity in which it is not meaningful, and another way of carrying it out in which it is meaningful; whatever explains this difference can then be built into the details of the case.

Now, advocates of the consensus view may insist that it is impossible for an activity, or part of a life, to be meaningful yet unambiguously bad in all other respects. In reply, I would make two points. The first is simply to claim that, intuitively, Frederick's activity is meaningful though bad in all other respects. Admittedly, this bald appeal to intuition may not have much dialectical force. But the second point is that if it were impossible for an activity to be meaningful yet unambiguously bad in all other respects, we should once again worry about the distinctness of meaning from other values.

This worry does not depend on the false assumption that it is impossible for $\mathrm{X}$ to be a distinct kind of final value if it cannot exist without other kinds of value existing. As we noted at the start, distinctness does not entail independence. Notably, some theories of virtue characterise virtue as excellent orientation to goodness. ${ }^{25}$ Similarly, some theories of wellbeing characterise it as loving or taking pleasure in the good.$^{26}$ According to these theories, virtue and well-being are distinct kinds of value even though they cannot exist independently of other goods. Instead, the worry is more specific. If meaning in life can exist only when the activities in which it inheres are good in other ways, it is hard to see how meaning is distinct from virtue or well-being in particular. If meaningfulness is distinct from both virtue and well-being, on the other hand, it is hard to see why Frederick's torturing could not be meaningful.

For these reasons I assume that it is possible for Frederick's torturing to be more meaningful than Eugene's. Does this make what Frederick does, or his life, in any way better than what Eugene does, or his life?

\footnotetext{
${ }^{25}$ For example, see Robert M. Adams, A Theory of Virtue: Excellence in Being for the Good (Oxford: Clarendon Press, 2006).

${ }^{26}$ For discussion of views of these sorts, see Shelly Kagan, 'Well-Being as Enjoying the Good', Philosophical Perspectives 23 (2009), pp. 253-72.
} 
It is hard to believe that it does. The two torturers simply draw on different sources of motivation. Frederick seems to have a more complex life, including a more complex mental life. But this does not make his life, or what he does, any better-except that it makes him, perhaps, more interesting than dull Eugene. Possibly we can imagine variants of the case in which Frederick gains some comfort from framing his torturing activity as part of a larger meaningful project of historical enquiry and re-enactment. Perhaps this distracts him from the full horror of what he does, which saves him some pain. Or perhaps others are interested in what he does, and perversely entertained by his accounts of it. In these variants, his life is in some respects better than Eugene's. But in all of them that is because it contains or causes some final value other than meaning, such as well-being.

\section{Conclusion}

The consensus view of meaning in life faces the significant challenge of simultaneously vindicating the distinctness and final value claims. One obvious way of vindicating the distinctness claim - by treating meaninglessness as the minimum quantity of meaning makes it harder to vindicate the final value claim. On the other hand, allowing negative meaning makes meaning in life resemble other candidate final values more closely, but thereby makes it harder to vindicate the distinctness claim.

I emphasised that this challenge should not be treated as a decisive criticism of the consensus view. It is too early to tell; perhaps the challenge can be met in some way that we have not considered. We have drawn a more tentative lesson from it: the apparent difficulty of meeting the challenge motivates exploring the prospects of departures from the consensus view.

I further argued that a promising strategy is to hold on to the distinctness claim but to give up the final value claim. We can then try to develop a theory of meaning in life that fits common judgements, and treats it as both distinct and ethically important. Its importance is, under these assumptions, purely instrumental. But this is perfectly compatible with the judgement that meaning in life is of great importance. Moreover, the claim that its importance is purely instrumental arguably has intuitively correct implications in cases of bad meaningful activity.

We should be wary in ethical theory of aversion to merely instrumental value. Philosophers' eyes tend to be drawn to final goods. But the nature and importance of final goods is not all there is to know about value. We also need to know how final goods combine 
or fail to combine with each other in a single life or outcome; the ways in which they fit together or crowd each other out. These matters have to do with causal and other practical constraints on the combination of goods. To know these vitally important things we must know about instrumental value, not just final value. The real significance of meaning in life may lie in this domain. ${ }^{27}$

\section{Bibliography}

Adams, Robert M. A Theory of Virtue: Excellence in Being for the Good. Oxford: Clarendon Press, 2006.

Brogaard, Berit and Barry Smith. 'On Luck, Responsibility and the Meaning of Life'. Philosophical Papers 34: 3 (2005), pp. 443-458.

Campbell, Stephen. M. and Sven Nyholm. 'Anti-Meaning and Why It Matters'. Journal of the American Philosophical Association 1 (2015), pp. 694-711.

Crescioni, A. Will and Roy F. Baumeister. 'The Four Needs for Meaning, the Value Gap, and How (and Whether) Society Can Fill the Void', in The Experience of Meaning in Life:

Classical Perspectives, Emerging Themes, and Controversies, edited by Joshua A. Hicks and Clay Routledge. Dordrecht: Springer, 2013, pp. 3-15.

Dorsey, Dale. 'Subjectivism without Desire'. Philosophical Review 121 (2012), pp. 407-42.

Kagan, Shelly. 'Well-Being as Enjoying the Good'. Philosophical Perspectives 23 (2009), pp. 253-72.

\footnotetext{
${ }^{27}$ For comments on earlier versions of this paper, I am very grateful to Jon Robson, Penelope Mackie, participants in the workshop 'Meaning in Life and Objective Values', Umeå University, $30^{\text {th }}$ November 2016, and two anonymous referees. I am especially grateful to Frans Svennson for organising the workshop and for discussion on that and other occasions. I am also very grateful to the Leverhulme Trust and the University of Nottingham for periods of research leave during which I worked on this paper.
} 
Kauppinen, Antti. 'Meaning and the Good Life', online at

https://www.academia.edu/28978139/Meaning_and_the_Good_Life accessed 2017.03.13,pp. $1-19$.

Kershnar, Stephen. 'Thad Metz's Fundamentality Theory of Meaning in Life: A Critical Review'. Science, Religion and Culture 1 (2014), pp.97-100.

Matheson, David. 'Creativity and Meaning in Life'. Ratio, online first (2016).

doi:10.1111/rati.12153

Metz, Thaddeus. 'Recent Work on the Meaning of Life'. Ethics 112 (2002), pp. 781-814.

Metz, Thaddeus. 'New Developments in the Meaning of Life'. Philosophy Compass 2 (2007), pp. 196-217.

Metz, Thaddeus. Meaning in Life. Oxford: Oxford University Press, 2013.

Metz, Thaddeus. 'Meaning as a Distinct and Fundamental Value: Reply to Kershnar'. Science, Religion and Culture 1 (2014), pp. 101-106.

Nozick, Robert. Philosophical Explanations. Cambridge, MA: Belknap Press, 1981.

Rawls, John. A Theory of Justice, revised edition. Cambridge, MA: Belknap Press, 1999 (1971).

Smuts, Aaron. 'The Good Cause Account of the Meaning of Life'. The Southern Journal of Philosophy 51: 4 (2013), pp. 536-562

Strawson, Galen. 'Against Narrativity'. Ratio XVII (2004), pp. 428-52.

Sumner, L. Wayne. Welfare, Happiness, and Ethics. Oxford: Clarendon Press, 1996.

Svennson, Frans. 'Why Subjectivism About Meaning In Life Might Not Be So Bad After All'. Unpublished MS, 2015. 
Tang, David, Nicholas J. Kelley, Joshua A. Hicks, and Eddie Harmon-Jones. 'Emotions and Meaning in Life: A Motivational Perspective', in The Experience of Meaning in Life:

Classical Perspectives, Emerging Themes, and Controversies, edited by Joshua A. Hicks and Clay Routledge. Dordrecht: Springer, 2013, pp. 117-128.

Višak, Tatjana. 'Understanding Meaning of Life in Terms of Reasons for Action'. Journal of Value Inquiry 51: 3 (2017), pp. 507-30.

Williams, Bernard A. O. 'Moral Luck', in Moral Luck: Philosophical Papers 1973-1980.

Cambridge: Cambridge University Press, 1981, pp. 20-39.

Wolf, Susan. 'Happiness and Meaning: Two Aspects of the Good Life'. Social Philosophy and Policy 14 (1997), pp. 207-25.

Wolf, Susan. Meaning in Life and Why it Matters. Princeton: Princeton University Press, 2010. 